ACCEPTED MANUSCRIPT

\title{
Silicon Y-bifurcated microchannels etched in 25 wt \% TMAH water solution
}

To cite this article before publication: Milce M. Smiljanic et al $2020 \mathrm{~J}$. Micromech. Microeng. in press https://doi.org/10.1088/1361-6439/abcb67

\section{Manuscript version: Accepted Manuscript}

Accepted Manuscript is "the version of the article accepted for publication including all changes made as a result of the peer review process, and which may also include the addition to the article by IOP Publishing of a header, an article ID, a cover sheet and/or an 'Accepted Manuscript' watermark, but excluding any other editing, typesetting or other changes made by IOP Publishing and/or its licensors"

This Accepted Manuscript is @ 2020 IOP Publishing Ltd.

During the embargo period (the 12 month period from the publication of the Version of Record of this article), the Accepted Manuscript is fully protected by copyright and cannot be reused or reposted elsewhere.

As the Version of Record of this article is going to be / has been published on a subscription basis, this Accepted Manuscript is available for reuse under a CC BY-NC-ND 3.0 licence after the 12 month embargo period.

After the embargo period, everyone is permitted to use copy and redistribute this article for non-commercial purposes only, provided that they adhere to all the terms of the licence https://creativecommons.org/licences/by-nc-nd/3.0

Although reasonable endeavours have been taken to obtain all necessary permissions from third parties to include their copyrighted content within this article, their full citation and copyright line may not be present in this Accepted Manuscript version. Before using any content from this article, please refer to the Version of Record on IOPscience once published for full citation and copyright details, as permissions will likely be required. All third party content is fully copyright protected, unless specifically stated otherwise in the figure caption in the Version of Record.

View the article online for updates and enhancements. 


\title{
Silicon Y-bifurcated microchannels etched in 25 wt $\%$ TMAH water solution
}

\author{
Milče M. Smiljanić ${ }^{1}$, Žarko Lazić $^{1}$, Milena Rašljić Rafajilović ${ }^{1}$, Katarina Cvetanović \\ Zobenica $^{1}$, Evgenija Milinković ${ }^{1}$ and Ana Filipović ${ }^{1}$
}

${ }^{1}$ University of Belgrade-Institute of Chemistry, Technology and Metallurgy, National Institute of the Republic of Serbia ICTM, Department of Microelectronic Technologies, Serbia

E-mail: smilce@nanosys.ihtm.bg.ac.rs

Received xxxxxx

Accepted for publication $\mathrm{xxxxxx}$

Published xxxxxx

\begin{abstract}
In this study, Y-bifurcated microchannels fabricated from a $\{100\}$ silicon in 25 wt $\%$ TMAH water solution at the temperature of $80{ }^{\circ} \mathrm{C}$ have been presented and analysed. We studied the etching of acute angles with sides along the $\langle$ n10 $>$ crystallographic directions in the masking layer where $1<\mathrm{n}<8$. We considered symmetrical acute corners in the masking layer with respect to the $\langle 100\rangle$ crystallographic directions. The angles between the appropriate $\langle$ n10 $\rangle$ and $\langle 100\rangle$ crystallographic directions were smaller than $45^{\circ}$. Moreover, we observed asymmetrical acute corners formed by the $\langle\mathrm{n} 10\rangle$ and $\langle\mathrm{m} 10\rangle$ crystallographic directions, where $m \neq n$. We found that the obtained convex corners were not distorted during etching. Consequently, it is not necessary to apply convex corner compensation. These fabricated undistorted convex corners represent the angles of the bifurcations. The sidewalls of the microchannels are defined by etched planes of the $\{n 11\}$ and $\{100\}$ families. Analytical relations were derived for the widths of the microchannels. The results enable simple and cost-effective fabrication of various complex silicon microfluidic platforms.
\end{abstract}

Keywords: Y bifurcation, microchannels, silicon, wet etching, TMAH

\section{Introduction}

Many studies have explored micromachining of (100) silicon substrates using anisotropic wet etching in $25 \mathrm{wt} \%$ tetramethylammonium hydroxide (TMAH) water solution [1$28]$. The etch rates of crystallographic planes [1-13,15,26], roughness of silicon surface after etching [2,7,13,25], and problems of convex corner etching and their solutions [14-28] have been investigated. Pattern design in the masking layer and solution anisotropy determine the etched threedimensional (3D) silicon shape. The distortion of convex corners during etching limits the production methods of complicated 3D silicon shapes [2,14,22,26]. The applied convex corner compensation depends on the design of the microdevice. Most of the designs are developed for the patterns with sides along the <110> crystallographic directions [15-24]. Some of them cause unwanted residues at the bottom of the silicon structure at the end of etching $[19,22]$. These residues can influence the functioning of microdevices. Moreover, the sides of the pattern designs are only along the most common crystallographic directions $<110\rangle$ and $<100\rangle$.

In our previous work [26-28], we presented a comprehensive study on the etching of patterns with sides along the $\langle$ n10 $\rangle$ crystallographic directions. In these papers, we presented etching of the (100) silicon in $25 \mathrm{wt} \%$ TMAH water solution at the temperature of $80{ }^{\circ} \mathrm{C}$, using silicon dioxide as a masking layer. We explored the etching of mask patterns in the shapes of squares and parallelograms in the corresponding studies. In Ref.[26], we studied square islands 
and apertures with sides along the <n10> crystallographic directions, where $0 \leq \mathrm{n}<10$. In [27-28], we analysed islands in the shapes of parallelograms with sides along predetermined crystallographic directions $<$ n10 $\rangle(1<\mathrm{n}<8)$ and $\langle 100\rangle$. During the etching of patterns presented in
Ref.[28], sustainable types of 3D silicon shapes were obtained. It was concluded that the convex corners were not distorted, although, no convex corner compensation was applied.

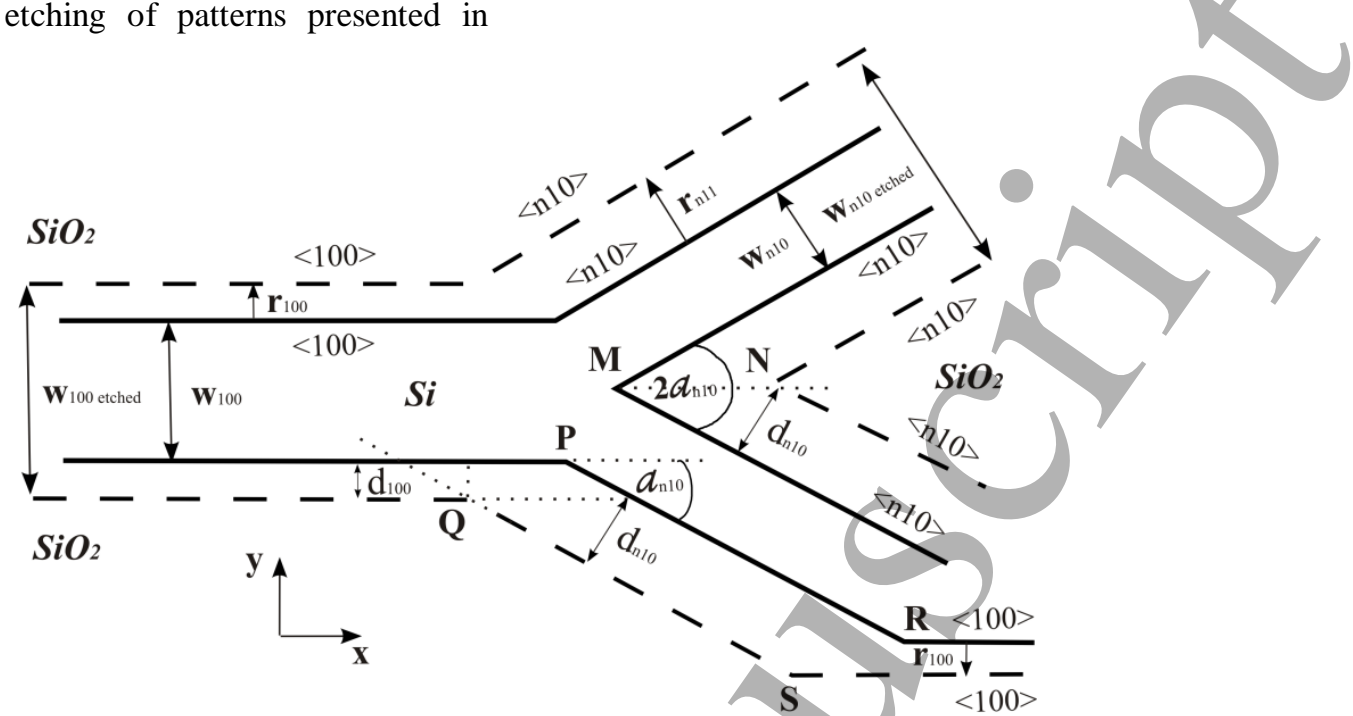

(a)

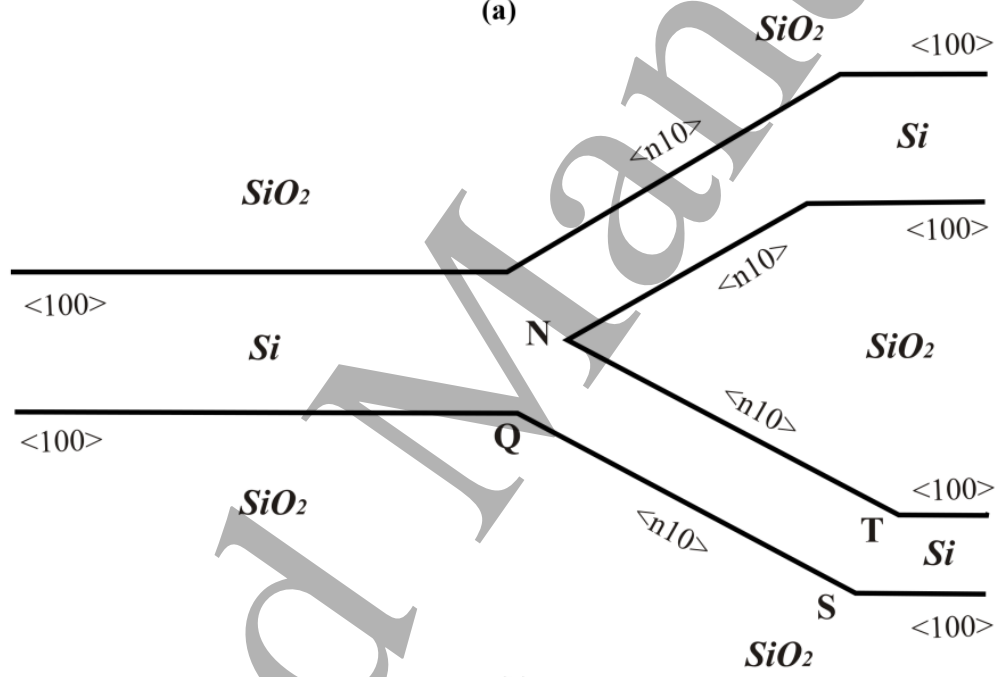

(b)

Figure 1. a) Schematic picture of Y-bifurcated microchannel's etching evolution. b) Schematic picture of two level microfluidic network.

This technical note presents our new results on the (100) silicon etching in $25 \mathrm{wt} \%$ TMAH water solution at a temperature of $80^{\circ} \mathrm{C}$. We analysed convex corners with sides along the $\langle$ n10 $>$ crystallographic directions in the masking layer where $1<\mathrm{n}<8$. These convex corners were stable during etching. As there the compensation that typically leaves residues is not required, our findings allow fabrication of good quality Y-bifurcated microchannels for microfluidics [29-31]. In Ref.[32], the authors fabricated bifurcated silicon channels in the $\langle 100\rangle$ and $\langle 110\rangle$ directions using TMAHTriton etchant to reduce convex corner underetching. In addition to all the etched silicon microstructures without any compensation using 25 wt \% TMAH+NC-200, authors in Ref.[22] presented a Y-bifurcated microchannel. We demonstrate basic designs with sides along predetermined $<$ n10 $>$ crystallographic directions different from the standard $<110>$ direction etched in pure $25 \mathrm{wt} \%$ TMAH water solution. The presented convex corners provide possibilities for various novel designs with angles that are deflected from the standard $\langle 100\rangle$ direction. The combination of presented basic patterns allows the production of complex silicon microfluidic platforms, especially networks of microchannels [33]. 


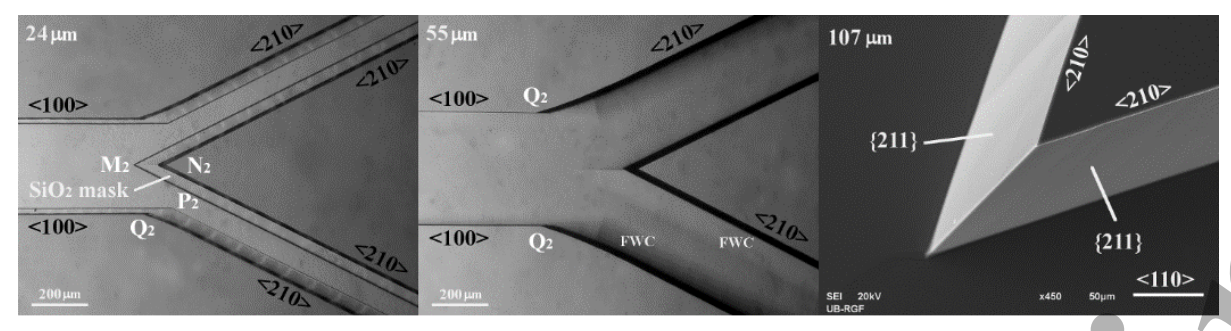

(a)
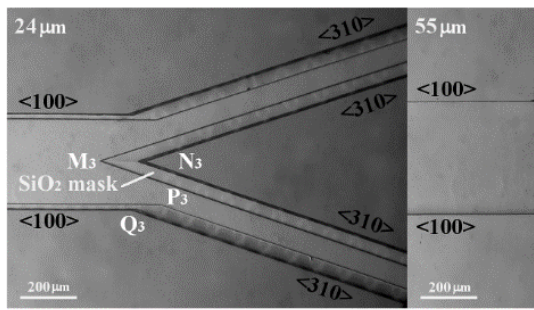

Figure 2. Photographs and SEM microphotographs of etching evolution of Y-bifurcated microchannels with the sides along crystallographic directions $\langle 100\rangle$ and: a) $\langle 210\rangle$, b) $\langle 310\rangle$. The $\mathrm{SiO}_{2}$ masking layer is present in the photographs for the etch depth of $24 \mu \mathrm{m}$. $\mathrm{SiO}_{2}$ is removed after reaching etch depths of 55 and $107 \mu \mathrm{m}$. The SEM microphotographs present enlarged convex corners etched from acute angles in the masking layer.

\section{Experimental setup}

In our experiments [15-16,26-28], we used phosphorusdoped $\{100\}$ - oriented 3" silicon wafers (SWI) with doublesided polished surfaces. The resistivity of the wafers was 1-5 $\Omega . \mathrm{cm}$. The wafers were cleaned in a standard procedure using a freshly prepared mixture of concentrated sulfuric acid and hydrogen peroxide, followed by RCA processing steps (mixture of ammonium hydroxide, hydrogen peroxide, and water; mixture of hydrochloric acid, hydrogen peroxide, and water). Wet thermal oxidation was performed at $1100^{\circ} \mathrm{C}$ to obtain a $\mathrm{SiO}_{2}$ masking layer. We defined bifurcations with sides along the predetermined crystallographic directions in the photolithographic processes using buffered hydrofluoric acid (BHF). After photolithographic processes, the wafers were again cleaned using the standard procedure. Native $\mathrm{SiO}_{2}$ was removed as the wafers were dipped for $30 \mathrm{~s}$ in hydrofluoric acid HF (10\%) and then rinsed in deionised water. Anisotropic etching was performed in pure TMAH 25 wt. \% water solution (Merck) at the temperature of $80^{\circ} \mathrm{C}$.

Wafers were etched in a thermostated glass vessel closed with a Teflon lid. The vessel was on the top of a hot plate where the TMAH solution temperature was stabilised within $\pm 0.5{ }^{\circ} \mathrm{C}$ by the electronic temperature controller. The evaporation during etching was minimised using a Teflon lid that included a water-cooled condenser. The glass vessel contained approximately $0.8 \mathrm{dm}^{3}$ of the solution. The velocity of the electromagnetically stirred TMAH solution was 300 rpm. We oriented the wafers vertically in a Teflon basket during etching. At the end of the silicon etching, the masking layer was removed using the BHF.

\section{Results and discussion}

Bifurcated microchannels are designed with sides along the predetermined crystallographic directions $\langle$ n10 $\rangle(1<\mathrm{n}<8)$ and $\langle 100\rangle$, as shown in Figures 1-4. Bifurcations consist of two obtuse and one acute angle in the masking layer, with the values mentioned in Table 1. The obtuse angles in the masking layer (angle $\mathrm{P}$ in Figure 1(a), angles $\mathrm{P}_{\mathrm{n}}, \mathrm{n}>1$ in Figures 2-4) were formed by the $\langle$ n10 $\rangle$ and $\langle 100\rangle$ crystallographic directions, as in Ref.[28]. In the first case of $n=2$, the sidewalls are defined by $\{211\}-\{311\}$ families along the initial $\langle 210\rangle$ crystallographic direction (Figure 2a), as in the case of an etched square with sides along the $\langle 210\rangle$ crystallographic directions presented in Ref.[26,28]. The transition from \{211\} to $\{311\}$ planes is smooth. In addition, a smooth distortion of the obtuse angle $\mathrm{Q}_{2}$ is observed because it is defined by the $\{100\}$ and $\{311\}$ planes. The sidewalls of the etched obtuse angle in all other cases $(n>2)$ are defined only by the $\{n 11\}$ and $\{100\}$ families, as shown in Figures 2(b),3,4. The sidewalls aligned with the $\langle$ n10 $\rangle$ direction belong to the $\left\{\right.$ 111\} crystallographic planes, as in Ref.[28]. The angles $\gamma_{n 11}$ between the $\{n 11\}$ and $\{100\}$ planes are given in Table 2 . In the cases where $n>2$, the sidewalls developed at the obtuse angles $\mathrm{Q}_{\mathrm{n}}$ sustain as the etching continues [28]. 
The acute angles (angle $\mathrm{M}$ in Figure 1(a)) of the presented bifurcations are formed in symmetrical $\langle$ n10 $\rangle$ crystallographic directions with respect to the predetermined $<100\rangle$ crystallographic direction. Angles $\alpha_{n 10}$ between the appropriate $\langle$ n10 $\rangle$ and $\langle 100\rangle$ crystallographic directions are smaller than $45^{\circ}$. The acute angles in the masking layer are represented by $2 \alpha_{n 10}$, which are provided in Table 1 . The sidewalls of acute angles aligned to the $\langle$ n10 $\rangle$ directions are from the $\{$ n11 $\}$ families $[26,28]$. We also analysed two acute angles formed by the $\langle\mathrm{n} 10\rangle$ and $\langle\mathrm{m} 10\rangle$ crystallographic directions, where $m \neq n$, as shown in Figure 5. The sidewalls of these asymmetrical acute angles in Figure 5 are defined by the $\{311\}$ and $\{411\}$ families as well as by the $\{311\}$ and $\{511\}$ families. These acute angles can be used for the fabrication of bifurcations with asymmetrical microchannels. In addition, the 3D silicon shape obtained in Figure 5 can

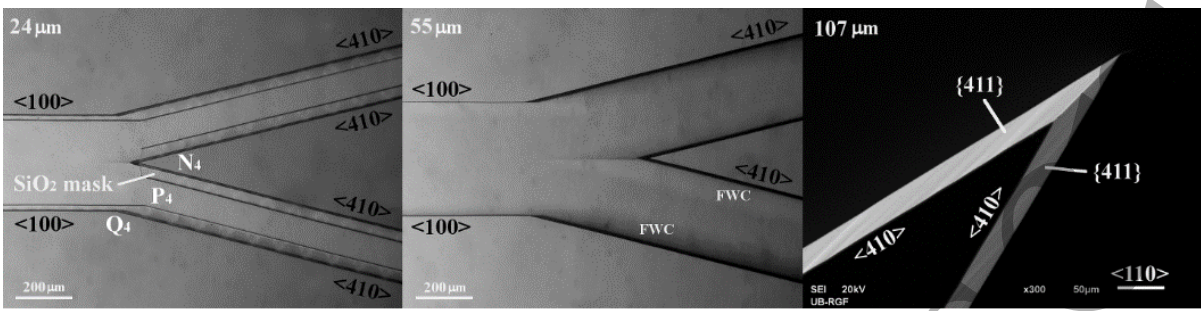

(a)

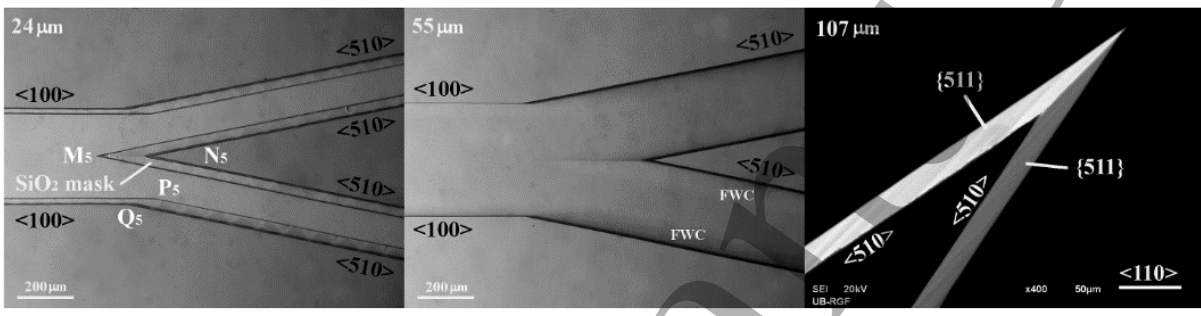

(b)

Figure 3. Photographs and SEM microphotographs of etching evolution of Y-bifurcated microchannels with sides along crystallographic directions $\langle 100\rangle$ and: a) $\langle 410\rangle$, b) $\langle 510\rangle$. The $\mathrm{SiO}_{2}$ masking layer is present in the photographs for the etch depth of $24 \mu \mathrm{m}$. $\mathrm{SiO}_{2}$ is removed after reaching etch depths of 55 and $107 \mu \mathrm{m}$. The SEM microphotographs present enlarged convex corners etched from acute angles in the masking layer.

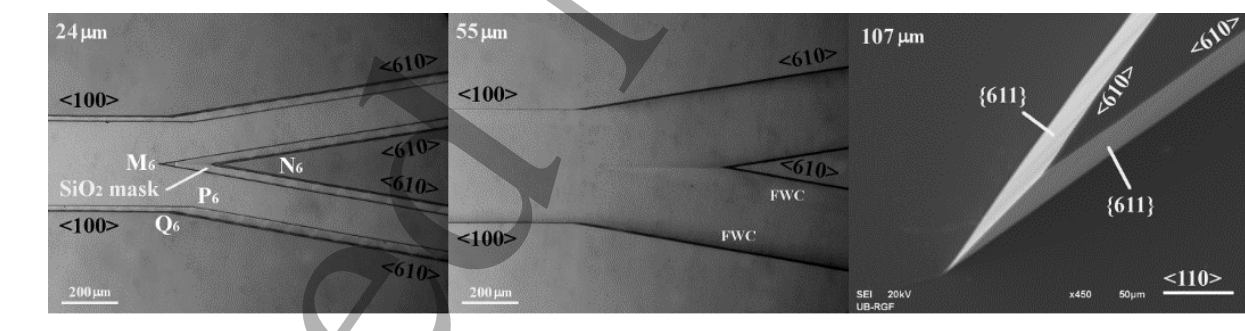

(a)

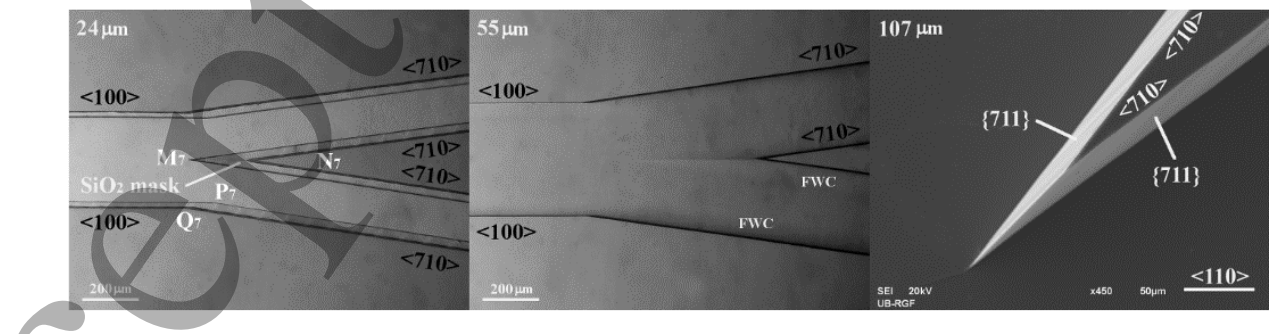

(b)

Figure 4. Photographs and SEM microphotographs of etching evolution of Y-bifurcated microchannels with sides along crystallographic directions $\langle 100\rangle$ and: a) $\langle 610\rangle$, b) $\langle 710\rangle$. The $\mathrm{SiO}_{2}$ masking layer is present in the photographs for the etch depth of $24 \mu \mathrm{m}$. $\mathrm{SiO}_{2}$ is removed after reaching etch depths of 55 and $107 \mu \mathrm{m}$. The SEM microphotographs present enlarged convex corners etched from acute angles in the masking layer. 
be used as an integrated obstacle in microchannels on the platforms that are based on obstacle mechanisms such as micromixers [28]. As no new crystallographic planes appear during etching, none of the observed acute angles is distorted

Fluid flow in fabricated microchannels can be affected by the residues caused by the convex corner compensation. As no convex corner compensation is applied, there are no residues at the bottom of the etched silicon microchannels. There are facets with a weak curvature (FWC) [15] at every connection of the sidewalls with the bottom surface. The appearance of FWC is inevitable and cannot be compensated in any way. The angles of these facets cannot be determined because of the smooth transition from the bottom to the sidewalls. The appearance of the smooth FWC can influence the crosssectional shapes of the obtained microchannels.

The widths of the etched microchannels $w_{\text {100etched }}$ and $w_{n 10 e t c h e d}$, as presented in Figure 1(a), depend on the etch depth $d_{100}$ :

$w_{100 \text { etched }}=w_{100}+2 d_{100}$

$w_{n 10 e t c h e d}=w_{n 10}+2 \frac{r_{n 11}}{r_{100} \sin \gamma_{n 11}} d_{100}=w_{n 10}+2 U_{n 11} d_{100}$ (2)

$$
U_{n 11}=\frac{r_{n 11}}{r_{100} \sin \gamma_{n 11}}
$$

where $w_{100}$ and $w_{n 10}$ are the widths of the microchannel with sides along the $\langle 100\rangle$ and $\langle$ n10 $>$ crystallographic directions, respectively, before etching, $r_{n 11}$ is etch rate of the $\{\mathrm{n} 11\}$ crystallographic planes and $U_{n 11}$ is the undercut ratio defined only along one $\langle\mathrm{n} 10\rangle$ side of the parallelogram [28]. In Table 2 , we provide the values of $r_{n 11}, \gamma_{n 11}$, and $U_{n 11}[26,28]$. The value of $\{100\}$ etch rate $r_{100}$ is $0.46 \mu \mathrm{m} / \mathrm{min}$ [26]. As an example, we also present in Table 2 widths wnloetched that are calculated using formula (2) and measured in experiments for etch depth of $55 \mu \mathrm{m}$.

The vertices of the acute and obtuse angles in the masking layer change their position during etching, as indicated by $\mathrm{P} \rightarrow \mathrm{Q}$ and $\mathrm{M} \rightarrow \mathrm{N}$ in Figure 1. The position of the vertices depends on the values of $r_{n 11}$ and $r_{100}$, and should be considered during the design of bifurcations:

$$
\begin{aligned}
& d_{n 10}=U_{n 11} d_{100} \\
& X_{P \rightarrow Q}=\frac{d_{n 10}}{\sin \alpha_{n 10}}-\frac{d_{100}}{\operatorname{tg} \alpha_{n 10}}=d_{100}\left(\frac{U_{n 11}}{\sin \alpha_{n 10}}-\frac{1}{\operatorname{tg} \alpha_{n 10}}\right) \\
& Y_{P \rightarrow Q}=d_{100} \\
& X_{M \rightarrow N}=\frac{d_{n 10}}{\sin \alpha_{n 10}}=d_{100} \frac{U_{n 11}}{\sin \alpha_{n 10}}
\end{aligned}
$$

where, $X_{P \rightarrow Q}, Y_{P \rightarrow Q}$ and $X_{M \rightarrow N}$ are the absolute displacements of vertices in the $x$ and $y$ directions $(<100>$ crystallographic

\begin{tabular}{|c|c|c|c|}
\hline $\begin{array}{l}\text { Crystallographic } \\
\text { direction }\langle\text { n10 }\end{array}$ & $\begin{array}{c}\text { Angle between } \\
<\text { n10>and }<100> \\
\alpha_{n 10}\left[{ }^{\circ}\right]\end{array}$ & $\begin{array}{l}\text { Acute angle } \\
2 \alpha_{\mathrm{n} 10}\left[{ }^{\circ}\right]\end{array}$ & $\begin{array}{c}\text { Obtuse angle } \\
{\left[{ }^{\circ}\right]}\end{array}$ \\
\hline$\langle 210\rangle$ & 26.6 & 53.2 & 153.4 \\
\hline$\langle 310\rangle$ & 18.4 & 36.8 & 161.6 \\
\hline$\langle 410\rangle$ & 14 & 28 & 166 \\
\hline$<510\rangle$ & 11.3 & 22.6 & 168.7 \\
\hline$<610\rangle$ & 9.5 & 19 & 170.5 \\
\hline$\langle 710\rangle$ & 8.1 & 16.2 & 171.9 \\
\hline
\end{tabular}
directions). The derived analytical relation allows good control over the dimensions during the etching of the silicon structure in anisotropic TMAH 25 wt. \% water solution.

\begin{tabular}{|c|c|c|c|c|c|c|c|}
\hline $\begin{array}{l}\text { Crystallograhic } \\
\text { plane }\{\text { n11 }\}\end{array}$ & 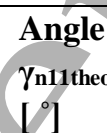 & $\begin{array}{l}\text { Angle } \gamma_{\mathrm{n} 11} \\
{[26]} \\
{\left[{ }^{\circ}\right]}\end{array}$ & $\begin{array}{l}\text { Etch rates } \\
r_{n 11 \quad[26]} \quad[\mu \mathrm{m} / \mathbf{m i n}]\end{array}$ & $\begin{array}{l}U_{n 11} \\
{[28]}\end{array}$ & $\begin{array}{l}w_{n 10} \\
{[\boldsymbol{\mu m}]}\end{array}$ & $\begin{array}{l}\text { W }_{\text {n10etched_c }} \\
{[\boldsymbol{\mu m}]}\end{array}$ & $\begin{array}{l}w_{n 10 e t c h e d \_m} \\
{[\boldsymbol{\mu \mathbf { m } ]}}\end{array}$ \\
\hline$\{211\}$ & 65.9 & 66.7 & 0.87 & 2.06 & 70 & 297 & 306 \\
\hline$\{311\}$ & 72.5 & 74.2 & 0.93 & 2.10 & 70 & 301 & 307 \\
\hline$\{411\}$ & 76.4 & 78.7 & 0.85 & 1.89 & 90 & 298 & 299 \\
\hline$\{511\}$ & 78.9 & 80.9 & 0.81 & 1.78 & 100 & 296 & 288 \\
\hline$\{611\}$ & 80.7 & 81 & 0.73 & 1.61 & 120 & 297 & 288 \\
\hline$\{711\}$ & 82 & 83.1 & 0.69 & 1.52 & 130 & 297 & 286 \\
\hline
\end{tabular}

Table 1. Acute and obtuse angles of microchannels.

Table 2. Angles $\gamma_{\mathrm{n} 11}$ between planes $\{\mathrm{n} 11\}$ and $\{100\}$, etch rates $r_{n 11}$, ratios of undercut and etch depth $U_{n 11}$, predetermined widths $w_{n 10}$, calculated $w_{n 10 e t c h e d} \_$and measured $w_{n 10 e t c h e d} m$ widths for etched depth of $55 \mu \mathrm{m}$. 
In our previous work [26], we analysed the etching of square apertures with sides along the $\langle$ n10 $\rangle$ crystallographic directions. In cases where $n>1$, the initial right concave corners changed into three new concave corners during etching. One of the angles is formed by the $\langle$ n10 $\rangle$ and $\langle 100\rangle$ crystallographic directions (angle R in Figure 1(a)), and the value of the concave angle in the masking layer is $180^{\circ}+\alpha_{n 10}$. The sidewalls of the concave angle are also defined by planes of $\{n 11\}$ and $\{100\}$ families, in the same way as the etched obtuse angle of bifurcation explained above.

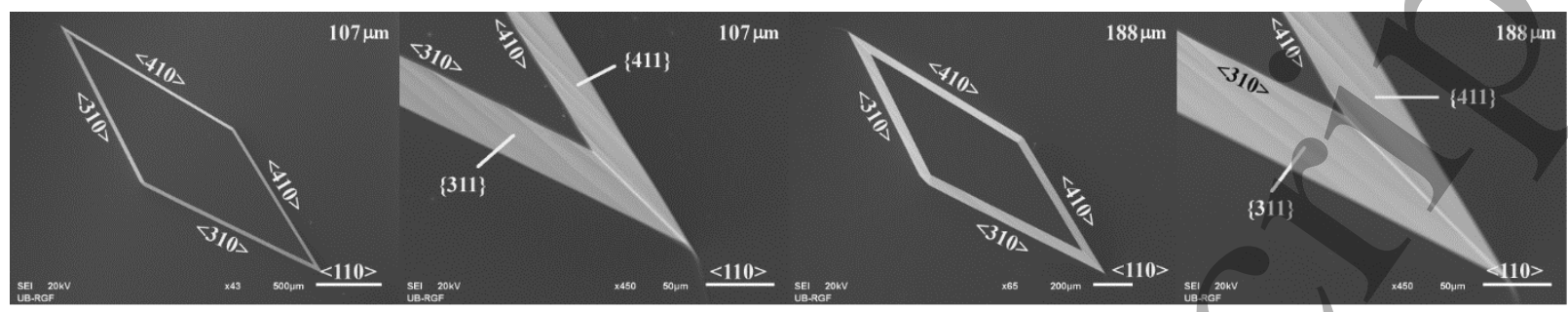

(a)

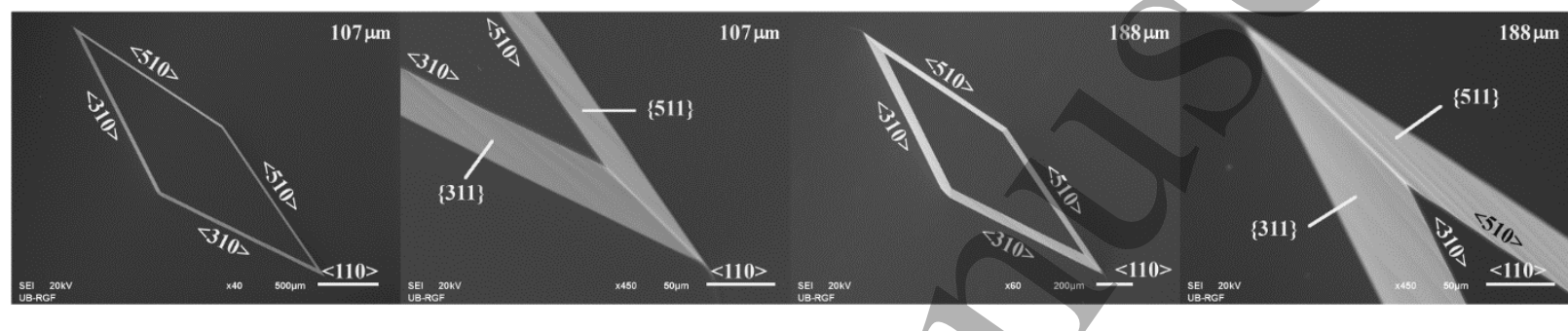

(b)

Figure 5. SEM microphotographs of etching evolution of 3D silicon structure with sides in the masking layer along crystallographic directions: a) $\langle 310\rangle$ and $\langle 410\rangle$, b) $\langle 310\rangle$ and $\langle 510\rangle$. Enlarged convex corners etched from asymmetrical acute angles in the masking layer are given. $\mathrm{SiO}_{2}$ is removed after reaching etch depths of 107 and $188 \mu \mathrm{m}$.

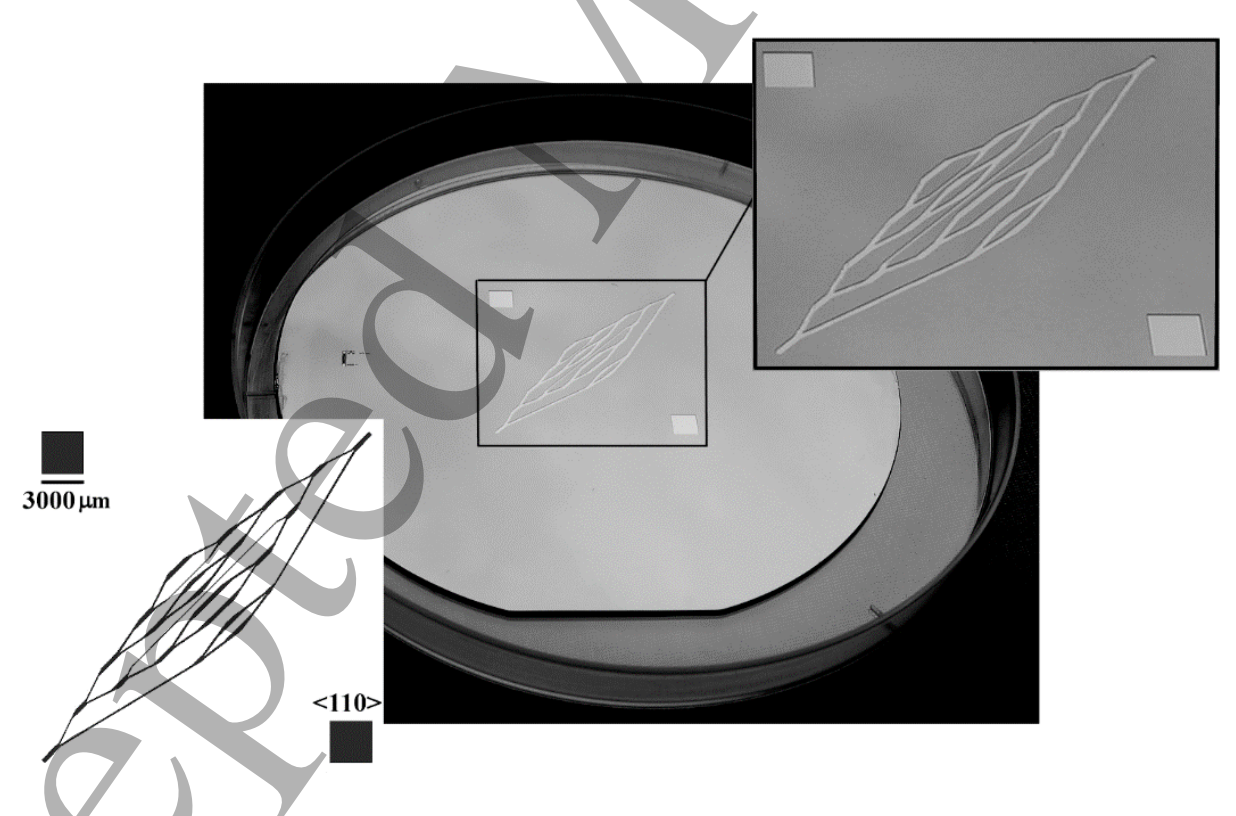

Figure 6. Mask pattern and photograph of multilevel microfluidic network of etched microchannels. The etch depth is $55 \mu \mathrm{m}$.

Etching of various convex corners without compensation presented in this study, together with undistorted convex and concave angles from our previous work $[26,28]$ enables the fabrication of multilevel microfluidic networks, as shown in
Figure 1(b),6. Figure 6 shows etched bifurcations with different angles and widths of microchannels that present an example of a complex microfluidic network. The combination of microchannels with sides along $\langle$ n10 $\rangle$ and $\langle 100\rangle$ 
crystallographic directions has a significant practical impact because of its simple design and fabrication. In addition, wet etching of silicon in $25 \mathrm{wt} \%$ TMAH water solution is a costeffective process in comparison with dry etching commonly used for various microfluidic platforms [34-37]. The doublesided polished wafer enables double-sided etching to form microchannels on the top side. It also provides inlets and outlets for fluid flow at the bottom side. In this case, micromachining of Pyrex glass is not necessary. The doubleside etched wafers anodically bonded to Pyrex glasses on the silicon top sides are more rigid microfluidic platforms than those obtained from polydimethylsiloxane (PDMS) [38-39]. The anodic bonding of Pyrex glass and silicon wafers provides good sealing. In addition, there is no gas permeability as in the case of the most common platforms based on PDMS [40]. Predictable evolution of explored convex and concave corners in this study can be used in future fabrication of other silicon microdevices and platforms. The proposed technique allows the fabrication of predetermined convex corners for microfluidic applications. However, it cannot provide a method to fabricate circular or other irregular geometries of the microchannels.

\section{Conclusion}

In this technical note, the silicon etching of Y-bifurcated microchannels using $25 \mathrm{wt} \%$ TMAH water solution at the temperature of $80{ }^{\circ} \mathrm{C}$ has been explored. The sides of the microchannels were designed along the $\langle$ n10 $\rangle$ and $\langle 100\rangle$ crystallographic directions. We demonstrated basic designs of bifurcations with sides along crystallographic directions that are different from the commonly used $\langle 110\rangle$ direction. We obtained convex corners of silicon microfluidic structures that are not distorted during etching, and consequently, no convex corner compensation was applied. The sidewalls of the microchannels are defined by etched planes of the $\{$ n11 $\}$ and $\{100\}$ families. Analytical relations for the position of angle vertices are determined in order to obtain controllable shapes of microchannels. The presented simple mask designs can be used to fabricate complex microfluidic networks by a costeffective process with good control over microchannel dimensions.

\section{Acknowledgements}

The authors acknowledge funding provided by the Institute of Chemistry, Technology and Metallurgy through a grant from the Ministry of Education, Science and Technological Development of the Republic of Serbia (Grant No. 451-0368/2020-14/200026).

\section{References}

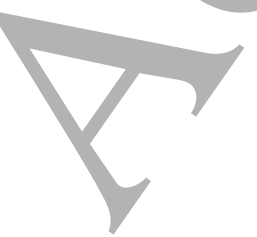

[1] Gosalvez MA, Zubel I and Viinikka E 2010 Wet Etching of Silicon in Handbook of Silicon Based MEMS Materials and Technologies, Lindroos V, Tilli M, Lehto A, Motooka T (William Andrew, Elsevier). https://www.elsevier.com/books/handbook-of-silicon-basedmems-materials-and-technologies/tilli/978-0-8155-1594-4

[2] Frühauf J 2005 Shape and Functional Elements of the Bulk Silicon Microtechnique(Springer-Verlag, Berlin). http://www.springer.com/gp/book/9783540221098

[3] Pal P and Sato K 2017 Silicon wet etching for MEMS (Taylor\&Francis, Pan Stanford Publishing, Singapore)

[4] Shikida M, Sato K, Tokoro, K and Uchikawa D 2000 Differences in anisotropic etching properties of $\mathrm{KOH}$ and TMAH solutions Sensors and Actuators A 80 179-188. https://doi.org/10.1016/S0924-4247(99)00264-2

[5] Sato K, Shikida M, Yamashiro T, Asaumi K, Iriye Y and Yamamoto M 1999 Anisotropic etching rates of single-crystal silicon for TMAH water solution as a function of crystallographic orientation Sensors and Actuators A 73 131137. https://doi.org/10.1016/S0924-4247(98)00271-4

[6] Resnik D, Vrtacnik D, Aljancic U and Amon S 2000 Wet etching of silicon structures bounded by (311) sidewalls Microelectronic Engineering 51-52555-566. https://doi.org/10.1016/S0167-9317(99)00519-5

[7] Resnik D, Vrtacnik D and Amon S 2000 Morphological study of $\{311\}$ crystal planes anisotropically etched in (100) silicon role of etchants and etching parameters J. Micromech. Microeng. 10 430-439. https://doi.org/10.1088/0960$1317 / 10 / 3 / 319$

[8] Yang H, Bao M, Shen S, Li X, Zhang D and Wu G 2000 A novel technique for measuring etch rate distribution of $\mathrm{Si}$ Sensors and Actuators A 79 136-140. https://doi.org/10.1016/S0924-4247(99)00270-8

[9] Landsberger L M, Naseh S, Kahrizi M and Paranjape M1996 On Hillocks Generated During Anisotropic Etching of Si in TMAH IEEE J. Microelectromech. Syst. 52 106-116. DOI: 10.1109/84.506198

[10] Zubel I, Barycka I, Kotowska K and Kramkowska M 2001 Silicon anisotropic etching in alkaline solution IV: The effect of organic and inorganic agents on silicon anisotropic etching processSensors and Actuators A 87 163-171. https://doi.org/10.1016/S0924-4247(00)00481-7

[11] Zubel I 2019 Anisotropic etching of Si J. Micromech. Microeng. 29 093002. https://doi.org/10.1088/13616439/ab2b8d

[12] Shen J, Chen Y, Zhang F, Zhang D and Gan Y 2019 Morphological and crystallographic evolution of patterned silicon substrate etched in TMAH solutions Applied Surface Science 496143720

[13] Sarro PM, Brida D, Vlist W vd and Brida S 2000 Effect of surfactant on surface quality of silicon microstructures etched in saturated TMAHW solutions Sensors and Actuators A 85 340-345. https://www.sciencedirect.com/science/article/pii/S092442470 0003174

[14] Trieu H K and Mokwa W 1998 A generalized model describing corner undercutting by the experimental analysis of TMAH/IPA J. Micromech. Microeng. 8 80-83. https://doi.org/10.1088/0960-1317/8/2/009 
[15] Smiljanić M M, Jović V and Lazić Ž 2012 Maskless convex corner compensation technique on a $\left(\begin{array}{lll}1 & 0 & 0\end{array}\right)$ silicon substrate in a 25 wt. \% TMAH water solution J. Micromech. Microeng. 22 115011. https://doi.org/10.1088/0960-1317/22/11/115011

[16] Smiljanić M M, Radjenović B, Radmilović-Radjenović M, Lazić Ž and Jović V 2014 Simulation and experimental study of maskless convex corner compensation in TMAH water solutio J. Micromech. Microeng. 24115003. https://doi.org/10.1088/0960-1317/24/11/115003

[17] Mukhiya R, Bagolini A, Margesin B, Zen M and Kal S $2006<100>$ bar corner compensation for CMOS compatible anisotropic TMAH etching J. Micromech. Microeng. 16 24582462. https://doi.org/10.1088/0960-1317/16/11/029

[18] Bagolini A, Faes A and Decarli M 2010 Influence of Etching Potential on Convex Corner Anisotropic Etching in TMAH Solution IEEE J. Microelectromech. Syst. 195 1254-1259. DOI: 10.1109/JMEMS.2010.2067436

[19] Mukhiya R, Bagolini A, Bhattacharyya TK, Lorenzelli L and Zen M 2011 Experimental study and analysis of corner compensation structures for CMOS compatible bulk micromachining using $25 \mathrm{wt} \%$ TMAH Microelectronics Journal 42 127-134. https://doi.org/10.1016/j.mejo.2010.08.018

[20] Merlos A, Acero M C, Bao M H, Bausells J and Esteve J 1992 A study of the undercutting characteristics in the TMAH-IPA system J. Micromech. Microeng. 2 181-183. https://doi.org/10.1088/0960-1317/2/3/014

[21] Merlos A, Acero M C, Bao M H, Bausells J and Esteve J 1993. TMAH/IPA anisotropic etching characteristics Sensors and Actuators A 37-38 737-743 . https://doi.org/10.1016/09244247(93)80125-Z

[22] Pal P, Sato K, Shikida M and Gosalvez M A 2009 Study of corner compensating structures and fabrication of various shape of MEMS structures in pure and surfactant added TMAH Sensors and Actuators A 154192-203. https://doi.org/10.1016/j.sna.2008.09.002

[23] Pal P, Sato K and Chandra S 2007 Fabrication techniques of convex corners in a (100)-silicon wafer using bulk micromachining: a review J. Micromech. Microeng. 17 R111R133. https://doi.org/10.1088/0960-1317/17/10/R01

[24] Powell O and Harrison H B 2001 Anisotropic etching of $\{100\}$ and $\{110\}$ planes in (100) silicon J Micromech. Microeng 11 217-220. http://iopscience.iop.org/article/10.1088/0960$1317 / 11 / 3 / 309$

[25] Pal P, Sato K, Gosalvez M A and Shikida M 2007 Study of rounded concave and sharp edge convex corners undercutting in CMOS compatible anisotropic etchants J. Micromech. Microeng. 17 2299-2307. https://doi.org/10.1088/0960$\underline{1317 / 17 / 11 / 017}$

[26] Smiljanić M M, Radjenović B, Radmilović-Radjenović M, Lazić Ž and Jović V 2019 Evolution of Si crystallographic planes-etching of square and circle patterns in 25 wt \% TMAH Micromachines 10(2) 102.https://doi.org/10.3390/mi10020102

[27] Smiljanić M M, Lazić Ž, Radjenović B, RadmilovićRadjenović M, Jović V, Rašljić M, Cvetanović Zobenica K and Filipović A 2019 Etched Parallelogram Patterns with Sides Along $\langle 100\rangle$ and $\langle\mathrm{n} 10\rangle$ Directions in 25 wt \% TMAH Proc. 6th Conf. IcETRAN, Srebrno jezero, Serbia, Jun. 3-6.
[28] Smiljanić M M, Lazić Ž, Jović V, Radjenović B and Radmilović-Radjenović M 2020 Etching of Uncompensated Convex Corners with Sides along $\langle\mathrm{n} 10\rangle$ and $\langle 100\rangle$ in $25 \mathrm{wt} \%$ TMAH at $80^{\circ} \mathrm{C}$ Micromachines 11(3), 253. https://doi.org/10.3390/mi11030253

[29] Chen P C, Wang Y N and Wu M H 2015 Development of bifurcation microchannel to uniformly distribute a liquid plug, Chemical Engineering Research and Design 102253 260.https://doi.org/10.1016/j.cherd.2015.06.034

[30] Yang J, Pak Y E and Lee T R 2016 Predicting bifurcation angle effect on blood flow in the microvasculature Microvascular Research 108 22-28. DOI: 10.1016/j.mvr.2016.07.001

[31] Hymel S J, Lan H, Fujioka H and Khismatullin D B 2019 Cell trapping in Y-junction microchannels: A numerical study of the bifurcation angle effect in inertial microfluidics Phys. Fluids 31 082003.https://doi.org/10,1063/1.5113516

[32] Resnik D, Vrtačnik D, Aljančić U, Možek M, Penić S and Amon S 2007 Improvements of Roughness Control in Micromachining of Silicon Microchannels Proceedings of 5th International Conference on Nanochannels, Microchannels, and Minichannels, June 18-20, Puebla, Mexico ICNMM200730217 133-140. https://doi.org/10.1115/ICNMM2007-30217

[33] Olanrewaju A, Beaugrand M, Yafia M and Juncker D 2018 Capillary microfluidics in microchannels: from microfluidic networks to capillaric circuits Lab on a Chip 18 2323. DOI: $10.1039 / \mathrm{c} 81 \mathrm{c} 00458 \mathrm{~g}$

[34] Zhang L, Jones B, Majeed B, Nishiyama Y, Okumura Y and Stakenborg T2018 Study on stair-step liquid triggered capillary valve for microfluidic systems J. Micromech. Microeng. 28 065005. https://doi.org/10.1088/1361-6439/aab40c

[35] Agah M, Potkay J A, Lambertus G, Sacks R and Wise K D 2005 High-Performance Temperature-Programmed Microfabricated Gas Chromatography Column $J$. Microelectromech. Syst. 14 1039-1050.DOI: 10.1109/JMEMS.2005.856648

[36] Cho Y H, Yamamoto T, Sakai Y, Fujii T and Kim B 2006 Development of Microfluidic Device for Electrical/Physical Characterization of Single CellJ. Microelectromech. Syst. 15 1039-1050.DOI: 10.1109/JMEMS.2005.863738

[37] Mihailović M, Rops C M,Hao J, Mele L, Creemer J F and Sarro P M 2011 MEMS silicon-based micro-evaporator $J$. Micromech. Microeng. 21075007. https://doi.org/10.1088/0960-1317/21/7/075007

[38] Roh C, Lee J andKang C K 2016 Physical Properties of PDMS (Polydimethylsiloxane) Microfluidic Devices on Fluid Behaviors: Various Diameters and Shapes of PeriodicallyEmbedded Microstructures Materials 9 836. DOI: 10.3390/ma9100836

[39] Kang C K, Roh C and Overfelt R A 2013 Pressure-driven deformation with soft polydimethylsiloxane (PDMS) by a regular syringe pump: challenge to the classical fluid dynamics by comparison of experimental and theoretical results $R S C$ Advances 4 3102-3112. DOI: 10.1039/C3RA46708B

[40] Merkel T C, Bondar V I, Nagai K, Freeman B D and Pinnau I 2000 Gas sorption, diffusion, and permeation in poly(dimethylsiloxane) Polymer Physics 38 415-434 https://doi.org/10.1002/(SICI)10990488(20000201)38:3<415::AID-POLB8>3.0.CO;2-Z 